\title{
Science and Religion as Conceptual Schemes
}

Michele Marsonet, Prof.Dr

Vice-Rector for International Relations

University of Genoa, Genoa, Italy

\section{Abstract}

It is claimed sometimes that science on the one hand, and metaphysics and religion on the other, are incompatible conceptual schemes, in the sense that their statements are not inter-translatable. Our view, instead, is that science and religion deal with fundamentally diverse aspects of human experience. This means that, when each field stays within its proper domain, they can get along without problems. We must deny the still popular opinion that science is the only instrument which allows us to know nature. And we must also question the idea that science has acquired the exclusive right to speak about nature by progressively expelling metaphysics from the field. In order to do this one should, however, reject the neo-positivist characterization of the relations among science, metaphysics, theology and religion.

Keywords: Science, Religion, Metaphysics, Conceptual Schemes, Inter-translatability.

A conceptual scheme is, according to some dictionaries of philosophy, a set of concepts and propositions that provide a framework for describing and explaining items of some subject-matter along with criteria for recognizing which phenomena are to be considered deviant and in need of explanation, or the general system of concepts with which we organize our thoughts and perceptions. The outstanding elements of our everyday conceptual scheme include spatial and temporal relations, other persons, meaning-bearing utterances of others, and so on. To see the world as containing such things is to share this much of our conceptual scheme.

It follows from the previous general definitions that, when dealing with conceptual schemes, philosophers take into account the beliefs and assumptions formulated, for example, in science and morality. The comprehensive outlooks on the world generated by some community - when taken together - form an inclusive theory in terms of which the members of that community explain and interpret both their empirical and moral experience. The limits imposed on the term "community", on the other hand, are determined by philosophers themselves. "Community" may mean a particular society or all members of humankind.

The key point of the contemporary debate on conceptual schemes is, however, the following. Given the fact that thought (i.e. the manipulation of concepts) is not possible without the existence of language, conceptual schemes are most of the times (although not always) identified with languages or, even better, with sets of 
inter-translatable languages. If this is true, learning a language means to acquire the conceptual scheme it embodies and, as a matter of fact, according to this view a conceptual schemes is a language.

Moreover, one can ask whether there is only one conceptual scheme or many; if a plurality of conceptual schemes is admitted the problem of relativism arises. To sum up, a conceptual scheme is a "frame of reference", that is to say the view-point, or set of presuppositions or of evaluative criteria within which a person's perception and thinking always occur, and which constrains in a selective way the course and outcome of these human activities.

It is well known that, according to Donald Davidson, human beings would be unable to interpret speech from a different conceptual scheme as even meaningful. He claims that, since translation proceeds according to the "principle of charity", and since it must be possible for an omniscient translator to make sense of what we say and of how we behave, we can be assured that most of the beliefs formed within the commonsense conceptual framework are true.

Davidson thus challenges the scheme-content dualism, and his attack to the schemecontent distinction is supported by a set of arguments purporting to reject, first of all, the thesis that totally different conceptual schemes can actually exist. To put things in a sketchy manner, he equates having a conceptual scheme with having a language, so that we face the following elements: (1) language as the organizing force; (2) what is organized, referred to as "experience", "the stream of sensory experience", "physical evidence"; and finally (3) the failure of inter-translatability. It follows that:

It is essential to this idea that there be something neutral and common that lies outside all schemes [...] The idea is then that something is a language, and associated with a conceptual scheme, whether we can translate it or not, if it stands in a certain relation (predicting, organizing, facing, or fitting) with experience (nature, reality, sensory promptings). ${ }^{1}$

If this is the situation - Davidson goes on - then we could say that conceptual schemes that are different in a radical way from each other correspond to languages that are not inter-translatable. How can we, however, make sense of a total failure of intertranslatability among languages? For sure "we could not be in a position to judge that others had concepts or beliefs radically different from our own". ${ }^{2}$ Davidson's conclusion is that if one gives up the dualism of scheme and world, he will not give up

\footnotetext{
1 D. Davidson, "On the Very Idea of a Conceptual Scheme," Proceedings and Addresses of the American Philosophical Association, 47, 1974, pp. 5-20. The paper has been subsequently included in Inquiries into Truth and Interpretation, Clarendon Press, Oxford, 1984, pp. 183-198. Our quotations are drawn from the latter source. The present one is at pp. 190-191.

2 Ibid., p. 197.
} 
the world, but will instead be able to "re-establish unmediated touch with the familiar objects whose antics make our sentences and opinions true". ${ }^{3}$

On his part Richard Rorty fully endorses Davidson's stance. Starting from Quine's rejection of the notion of "meaning" as anything transcending what is contextually defined in predicting the behavior of other people, Rorty deems it impossible to distinguish an untranslatable language from no language:

Once we imagine different ways of carving up the world, nothing could stop us from attributing "untranslatable languages" to anything that emits a variety of signals. ${ }^{4}$

For example, we may imagine aliens who endorse a totally different view of the world, so that their language would - in principle - turn out to be untranslatable into our own. This means that they would carve up the world according to a completely different conceptual scheme. However Rorty thinks that:

[...] for all we know, our contemporary world is filled with unrecognizable persons. Why should we ignore the possibility that the trees and the bats and the butterflies all have their various untranslatable languages in which they are busily expressing their beliefs and desires to one another? [...] So I think that to rule the butterflies out is to rule out the Galactics and the Neanderthals, and that to allow extrapolation to the latter is to allow for the possibility that the very same beliefs and desires which our Galactic descendants will hold are being held even now by the butterflies. ${ }^{5}$

It follows that any language must, to count as a language, be translatable into our own, and that - quite surprisingly - the large majority of our present beliefs must be true. In other words,

[...] "the world" will just be the stars, the people, the tables, and the grass - all those things which nobody except the occasional "scientific realist" philosopher thinks might not exist. The fact that the vast majority of our beliefs must be true will, on this view, guarantee the existence of the vast majority of the things we now think we are talking about. ${ }^{6}$

By endorsing this line of thought, we no longer need the notion of "the world" conceived of as an "independent reality", a notion which is endorsed by those thinkers who claim that different conceptual schemes carve up the world differently.

Davidson's and Rorty's solution is radical, but we are bound to ask at this point what the expressions "reality" and "world" mean for them. Let us assume that they can be

\footnotetext{
3 Ibid., p. 198.

${ }^{4}$ R. Rorty, "The World Well Lost", in Consequences of Pragmatism, University of Minnesota Press, Minneapolis, 1994,6 th pr., p. 6.

5 Ibid., pp. 9-10.

${ }_{6}^{6}$ Ibid., p. 14.
} 
identified with the world of common sense which is formed by the familiar objects whose antics - as Davidson says - make our sentences and opinions true or false. These familiar objects are tables, chairs, houses, stars, etc., just as we perceive them in our daily life. One is not entitled to ignore, however, that the current discussion on the problem of scientific realism arise because there is a strong asymmetry between the commonsense view of the world and the scientific one. For instance, the table that we see with our eyes is not the same table that we "see" through the mediation of scientific instruments, and this fact is not trivial. It is rather easy to reach a high level of inter-subjective agreement among the individuals present in a room about the color, size and weight of a table, and it can also be granted that we form our beliefs in this regard by triangulating - in a Davidsonian sense - with our interlocutors and the surrounding environment. Such an agreement, however, becomes problematic when we try to reconcile this vision of the world with what present science tells us about it.

So being in touch with such familiar objects as tables, chairs and stars "most of the time" - as Rorty specifies - has a fundamental bearing only on the ontology of common sense, since our actual science shows that quite a different representation of reality can actually be provided. Or, even better, it shows that those objects might not exist as human beings perceive them. Naturally, one can always resort to an objection of the following kind: why should we deem the table viewed as a collection of subatomic particles more important than the table that our eyes see in daily life? After all, we can conduct our life well enough even ignoring what science claims (just like men did for many thousand years). This, however, looks like a serious under-evaluation of the scientific enterprise.

Davidson, as we said before, associates conceptual schemes with languages, and then adopts linguistic inter-translatability as the identity criterion for conceptual schemes themselves. Subsequently we are told that, in order to call something "a language," say Lo, we must be ready to accept the idea that the statements of Lo can be translated into those of our own language (let us call it $L_{1}$ ). It easily follows from this line of reasoning that, if this cannot be done, $L_{0}$ is not a language at all. According to Davidson,

[...] we must conclude [...] that the attempt to give a solid meaning to the idea of conceptual relativism, and hence to the idea of a conceptual scheme, fares no better when based on a partial failure of translation than when based on total failure. Given the underlying methodology of interpretation, we could not be in a position to judge that others had concepts or beliefs radically different from our own. ${ }^{7}$ 
One may point out, however, that linguistic inter-translatability cannot be such an absolute criterion, because in certain circumstances we are able to realize that some sort of language is used, even though we cannot translate it into our own language.

Larry Laudan has noted in this regard that there is no reason to assume the presence of different world-views only when there are no criteria of inter-translatability among them. He claims, in fact, that:

Only with the so-called linguistic turn have philosophers supposed that conceptual schemehood is to be understood in terms of non-translatability. Aristotle's cosmos and Einstein's universe represent very different world-views. With Davidson, I believe that each can be made intelligible to adherents of the other. But only someone as wedded to the translation thesis as Davidson is would imagine that the latter fact (viz., inter-translatability) constitutes grounds for denying that they represent different conceptual schemes. ${ }^{8}$

The absolute primacy that Davidson places on translatability should thus be rejected, hence Laudan's proposal to identify conceptual schemes on ontological, axiological and methodological - and not exclusively linguistic - criteria.

According to the neo-positivists, on the other hand, the sole true knowledge is empirical and based on immediate observation data; furthermore, they reject the Kantian synthetic a priori, even though Kant's influence on their philosophical outlook is quite strong. They attribute a key role to formal logic because, in their opinion, it allows us to formalize in a rigorous manner the intuitive inferential processes of ordinary language. In our day logical positivism is less popular than it used to be until a few decades ago, although maintaining a considerable influence. The so-called "postempiricist turn" questioned practically every single point of its general outlook on philosophy and the world.

If we try to identify the position of logical positivism in the map of contemporary philosophy, we will soon find out that it can be characterized by a few basic and radical theses:

(A) first, neo-positivism is not a philosophical system but, rather, a general attitude towards philosophy which denies any validity to the way philosophical work has been carried out in the past centuries;

(B) second, the logical positivists think that philosophy is not a speculative discipline: it is, rather, a logical-linguistic activity aimed at clarifying scientific propositions;

(C) third, there are only analytic (a priori) and synthetic (a posteriori) propositions. The first class is formed by logical and mathematical sentences, and the second

\footnotetext{
${ }^{8}$ L. Laudan, Beyond Positivism and Relativism, Westview Press, Boulder-San Francisco-Oxford, 1996, p. 13.
} 
by the sentences that can be found in the empirical sciences (where physics has a predominant role). As we said before, there is no Kantian "synthetic a priori".

It follows that the whole of human knowledge can be reduced to the two classes of sentences just mentioned, and this means that the only possible knowledge is given by science. Metaphysics and theology are thus meaningless, because their sentences do not comply with the rules set forth by logical analysis of language. What, then, is the philosopher's job? The neo-positivists answer that his task is to clarify the concepts used within empirical and formal sciences, while analytic philosophers stress instead the importance of ordinary language's analysis. But the outcome is in both cases clear: philosophy is linguistic analysis. It may be observed that neo-positivism certainly has some ancestors in the history of philosophy: the Sophists of ancient Greece like Protagoras, the nominalists of the Middle Ages like Ockham, the classical British empiricists (and especially Hume), the positivists of the 19th century like Comte. Their radicalism, however, is rather new. The logical positivists want to rebuild philosophy $a b$ initio, just making tabula rasa of what has been said and done in many centuries of philosophical speculation. The logical positivists of the past century are, then, despite their official lay spirit, the prophets of the "new scientific world-perspective". Their stance is a full-fledged scientism.

If we now examine the neo-positivists' alleged destruction of metaphysics and theology, it is possible to note that their attack actually missed the target due to its essential vagueness. Whom, or what, did they mean to attack? It is quite evident, for example, that the word "metaphyisics" has an incredibly high number of semantic and historical connotations. Plato and Aristotle are both metaphysicians, but is this sufficient to associate them? Hegel and Bergson, too, are metaphysicians, but who dares to claim that this fact makes them similar? We must recall that neo-positivism is, first of all, a reaction to the predominance of idealism in the Austrian and German academic circles during the last decades of the past century: the real targets of the members of the Vienna and Berlin Circles are in fact Hegel and their contemporary Martin Heidegger. Reading the famous essay by Rudolf Carnap "The Elimination of Metaphysics Through Logical Analysis of Language", ${ }^{9}$ it is easy to verify that, in order to show the purported meaningless of metaphysics, Carnap just analyses from a logical viewpoint some statements made by Hegel and Heidegger. But it is not difficult to understand that to criticize two particular philosophers does not imply attacking metaphysics as such: if it may be justified to claim that Heidegger often plays with the "magic of words", certainly this charge cannot be addressed to such rigorous philosophers as Aristotle or Leibniz. The situation becomes even clearer if one takes into account the classical essay Language, Truth and Logic, written in the 1930's by Sir

\footnotetext{
${ }^{9}$ R. Carnap, "The Elimination of Metaphysics Through Logical Analysis of Language", in A. J. Ayer (ed.), Logical Positivism, Free Press, New York 1959, pp. 60-81.
} 
Alfred J. Ayer. In this work, in fact, some remarks may be found that are very important for our purposes:

The belief that it is the business of the philosopher to search for first principles is bound up with the familiar conception of philosophy as the study of reality as a whole. And this conception is one which is difficult to criticize, because it is so vague. If it is taken to imply, as it sometimes is, that the philosopher somehow projects himself outside the world, and takes a bird's-eye view of it, then it is plainly a metaphysical conception. And it is also metaphysical to assert, as some do, that "reality as a whole" is somehow generically different from the reality which is investigated piecemeal by the special sciences. But if the assertion that philosophy studies reality as a whole is understood to imply merely that the philosopher is equally concerned with the content of every science, then we may accept it, not indeed as an adequate definition of philosophy, but as a truth about it. For we shall find, when we come to discuss the relationship of philosophy to science, that it is not, in principle, related to any one science more closely than to any other. In saying that philosophy is concerned with each of the sciences we mean also to rule out the supposition that philosophy can be ranged alongside the existing sciences, as a special department of speculative knowledge. Those who make this supposition cherish the belief that there are some things in the world which are possible objects of speculative knowledge and yet lie beyond the scope of empirical science. But this belief is a delusion. There is no field of experience which cannot, in principle, be brought under some form of scientific law, and no type of speculative knowledge about the world which it is, in principle, beyond the power of science to give. With this we complete the over throw of speculative philosophy. We are now in a position to see that the function of philosophy is wholly critical. ${ }^{10}$

On the one side Ayer's statements are very clear, but on the other they make us understand why the elimination of metaphysics could not be carried out (and this also justifies the length of our quotation). Let us consider, for instance, the concept of "reality as a whole". Ayer remarks that, in claiming to study reality as a whole, the metaphysician pretends to project himself outside the world taking a bird's-eye view of it. Assuming that any serious metaphysician really means to do this (which is, at least, questionable), there is a sentence that clearly reveals Ayer's hidden thoughts. In fact, he goes on claiming that "there is no field of experience which cannot, in principle, be brought under some form of scientific law, and no type of speculative knowledge about the world which it is, in principle, beyond the power of science to give". It is possible to note, then, that in pronouncing these statements Ayer is not talking about a reality which is investigated "piecemeal" by the special sciences. He speaks, instead, of: (1) 
a reality as such which has an exclusively empirical character, and (2) of a purported unified method which natural science uses in order to investigate reality.

But, at this point, two facts are neatly exhibited: (3) by reducing the whole of reality to empirical reality, Ayer is doing metaphysics. A metaphysical system needs not be idealistic: there is an empiricist metaphysics, as is shown by the developments of 19th century's mechanism; and (4) even Ayer's reality turns out to be "reality as a whole". Science, as conceived of by Ayer, is in fact nothing but a tool for knowing reality as such. We do not have the "elimination" of metaphysics here, but just the proposal of an empiricist brand of metaphysics. And this fact confirms, once more, that we must distinguish what the logical positivists say from what they actually do.

Now, the kinds of interactions that arise between science, metaphysics and religion can be classified as of conflict when one of the three fields purports to invade the concerns of the others; independence when it is thought that they are totally different realms of enquiry; dialogue when it is believed that the interests of the three fields overlap; integration when the aim is to unify the fields into one.

In the last two centuries the antagonism between religion and science was perceived as quite strong, especially in some philosophical traditions. Several thinkers claimed that any interaction between science and religion would cause open hostility, with religion assuming the role of the aggressor against scientific ideas. It should be noted, however, that such a view is less popular nowadays than in the near past. Today several historians of science reject it, stressing instead the fact that the conflict thesis has been overcome by the recent historical research.

It is well-known that many key figures of Western science were believers and Christians including, among others, Copernicus, Galileo, Kepler and Boyle. In our days most of the works on which the conflict thesis was based are deemed to be inaccurate. For example, many endorsed the thesis that the Catholic Church from the Middle Ages believed that the Earth was flat, and that modern science, liberated from religious dogmas, demonstrated that it is instead round. But such a thesis is mistaken, as some contemporary historians of science have shown.

As a matter of fact, science and religion deal with fundamentally diverse aspects of human experience and action. This means that, when each field stays within its proper domain, they can get along without problems (although not excluding the possibility of interrelations between them). Even the most famous contemporary scientist, Albert Einstein, supported somehow the compatibility of science and religion, saying that science can only ascertain what is, but not what should be, and outside of its domain value judgments of all kinds remain necessary. Religion, on the other hand, deals only with evaluations of human thought and action: it cannot justifiably speak of facts and relationships between facts. 
In order to endorse such a reasonable view, we must deny the still popular opinion that science is the only instrument which allows us to know nature. And we must also question the idea that science has acquired the exclusive right to speak about nature by progressively expelling metaphysics from the field. In order to do this one should, however, reject the aforementioned positivist and neo-positivist characterization of the relations among science, metaphysics, theology and religion.

In the final analysis we deem it necessary to point out that conceptual schemes are neither born out of nothing nor established on aprioristic bases. Their aim is to provide us with means for thinking about - and for speaking of - a reality which includes ourselves. In this sense science and religion turn out to be conceptual schemes which are compatible.

\section{Bibliography}

1. D. Davidson, "On the Very Idea of a Conceptual Scheme," Proceedings and Addresses of the American Philosophical Association, 47, 1974, pp. 5-20. Subsequently included in D. Davidson, Inquiries into Truth and Interpretation, Clarendon Press, Oxford, 1984, pp. 183-198.

2. R. Rorty, "The World Well Lost", in R. Rorty, Consequences of Pragmatism, University of Minnesota Press, Minneapolis, 1994, pp. 3-18.

3. L. Laudan, Beyond Positivism and Relativism, Westview Press, Boulder-San Francisco-Oxford, 1996.

4. R. Carnap, "The Elimination of Metaphysics Through Logical Analysis of Language", in A. J. Ayer (ed.), Logical Positivism, Free Press, New York 1959, pp. 60-81.

5. A.J. Ayer, Language, Truth and Logic, Macmillan, London, 1936. Reprinted by Penguin Books, London, 1990. 